\title{
PRINCIPLES OF FORMATION OF E-NETWORK KNOWLEDGE BASES IN THE FORMAT OF OPERATIONALLY STRUCTURED SCENARIOS
}

\begin{abstract}
A brief analysis of the principles of formation of modern network knowledge bases is given. The principles of management of information sources accompanying the process of formation of network knowledge bases are described. An example of existing systems of information and communication technologies for building and managing knowledge bases in the e-network is given. The tasks related to the functioning of information and communication technologies from the standpoint of the formation of modern e-network knowledge bases are set. The importance of the ontological approach to the design of network knowledge bases is determined. The approach and principles of formation of e-network knowledge base in the format of operationally structured scenarios are described, based on ontological aspects of their construction. The general graph-structure of the operationally-structured scenario of the knowledge base is given. Examples of their formation and visualization in the environment of the Web-software complex "Knowledge Baseline Script Editor" are given. Recommendations are given regarding the scope of use of the Web-software complex "Knowledge Baseline Script Editor".
\end{abstract}

Keywords: knowledge base, knowledge base script, script editor, operating structure.

\section{INTRODUCTION}

At the present stage of development of information technologies, the tendency of transfer of the sphere of the organization of process of information interaction in the environment of an e-network is formed. In such conditions, the key points are the form of organization and access to information sources of knowledge, which are placed in appropriate environments and can be accessed from anywhere and at any time.

Currently, in the development of network management systems for information sources that accompany the process of forming knowledge bases, the problematic task is not the software aspect, but the task of finding, formulating, structuring and presenting data from which knowledge is further formed.

\footnotetext{
1 Tetyana Kalna-Dubinyuk, Doctor of Science (Economics), Professor, National University of Life and Environmental Sciences of Ukraine, Kyiv, Ukraine; e-mail: tatiankd@yahoo.com. ORCID: 0000-0002-6770-4833.

2 Sergey Kalnoy, National Center of Junior Academy of Sciences of Ukraine, Senior researcher, Kyiv, Ukraine; e-mail: 13rom@ukr.net (corresponding author). ORCID: 0000-0001-5998-0339.
} 


\section{RESEARCH ANALYSIS AND PROBLEM STATEMENT}

Existing systems of information and communication technologies for building and managing knowledge bases in the e-network, have a broad theoretical and practical platform for research and use (Palagin, Kryvy, Petrenko, 2012; Boland, Singh, Salipante et al., 2001; Dalkir, Liebowitz, 2011; Krótkiewicz, Wojtkiewicz, 2009; Krótkiewicz, Wojtkiewicz, 2005; Nirenburg, Raskin, 2004; (Pugh, Prusak, 2013; O'Leary, 2016; Bera, Burton-Jones, Wand., 2011; Kalna-Dubinyuk, Rogoza, Samsonova et al., 2019; Demyanenko, Kalnoy, Strizhak, 2013; Kalnoy, 2019; Kalnoy, 2017). Recent theoretical research and practical results in this area are based on the construction of ontological models of knowledge bases and various ICTs based on them, such as: "Linguistic corpus", Exalead, Protégé, KAON2, Sesame, IBM SHER, Joseki Jena, Oracle Spatial, Krótkiewicz \& Wojtkiewicz, Palagin et al., O'Leary, and others. The use of such ICTs provides the construction of a network environment in which the mode of e-remote interaction between all its participants is supported. E-distance interaction is a network virtual environment in which all its participants carry out mainly individualized interaction both asynchronously and synchronously in time, mainly and in principle using electronic transport systems for the supply of information objects. One of the tasks of activity in this environment is to provide conditions for the effective use of information resources by all its participants. For this purpose means of formalization of various information sources of formation of knowledge taking into account specificity of process of e-network interaction are created.

The use of ICT software and information takes into account the fact that the volume and diversity of data and messages, according to different profiles of knowledge, is now so voluminous that there is a need to classify them in terms of belonging to the subject area or areas of interest of its participants. from the tasks they solve. Therefore, the use of these ICT software and information tools is focused on solving the following tasks:

- ensuring the possibility of operative organization of access to information sources of knowledge formation related to one subject area or areas of activity united by similar interests;

- support for the interaction of all participants within a non-single set of subject areas with the possibility of expanding this set;

- providing an opportunity to expand the list of sources and consumers of diverse information sources of knowledge formation, taking into account the results of all its participants;

- restricting access to information resources within a specific subject area or area of interest in connection with the possibility of solving the previous problem;

- ensuring the possibility of using information resources of several subject areas;

- ensuring the possibility of operative search of the source of necessary information resources by all its participants, as well as their operative exchange.

The ontological approach to designing a network knowledge base allows to create systems in which information sources of knowledge formation become ontologically structured and accessible to all its participants. The main advantages of this approach:

- the ontological approach gives the user a holistic, systematic view of a particular subject area;

- information sources about the subject area are presented in the same way, which simplifies their perception; 
- construction of the ontology allows you to quickly restore the missing logical connections of the subject area, where without violating the general structure of the knowledge base.

The importance of the ontological approach in creating a networked knowledge base is also due to the fact that if the information sources of knowledge formation are not described and replicated, they eventually become obsolete and irrelevant. On the contrary, information sources of knowledge formation, which are ontologically structured, distributed and used in a network way, can generate new knowledge. The ontological approach allows to present terms, concepts in such a way that they become suitable for computer processing, which leads the subject terminology to a formalized form and contributes to its equal understanding by all participants.

One of the approaches that will ensure the effective functioning of such a system is the construction of operationally structured scenarios of the knowledge base.

\section{RESEARCH RESULTS}

Each of the modern models of building knowledge bases has its own organizational structure, which forms the links between the information objects of the knowledge base. At the same time, almost all information objects of modern knowledge bases are fully integrated with its structure, which determines the large structural size of such knowledge bases. Management of such knowledge base systems takes up large computing resources, which directly affects the processing time of information. In addition, the systems are not focused on a personalized approach to their organization and management. To solve this problem, it is proposed to form the structure of the knowledge base in the form of a set of individual personalized e-scenarios, which within a given ontological structure, are operationally formed in accordance with the selected object and the task. If you need to create a new e-script, which would include other e-scripts stored in the knowledge base in the form of .xml files, they connect to it, either automatically in hyperlink format, or operationally, by embedding its information structure in the base the structure of the script being created. The combined script structure is then stored in a .xml file. Thus, the knowledge base in this case has a file operating structure, which includes ontologically structured e-scripts in .xml file format. That is, each e-script, within a given subject area, is personally formed according to the selected object and the task, and then stored in the .xml file format in the knowledge base.

"Operationally-structured knowledge base scenario" is one of the forms of organization of object-oriented knowledge base in a given subject area, which describes its functional and information structure step by step and is formalized in the form of operationally structured date blocks stored in $\mathrm{xml}$ format. files. The operational-structured $\mathrm{xml}$ knowledge base scripts created in this way can be combined or separated into other operational-structured xml knowledge base scripts, thus creating new transdisciplinary knowledge bases. In this case, operationally-structured xml scripts of the knowledge base can be formalized, both in the information-applied aspect (for example - a reference book or textbook) and in the functional aspect (for example - a training program as a functional structure of the educational process), or combine both of these formats.

In the theoretical aspect, the principles of formation of operational-structured scenarios of the knowledge base are based on the theory of ontologies and the theory of graphs. In 
formalized form, they are represented by a graph structure in which the vertices of the graph and their relationships are displayed in the form of subfolders (folders), defining the name of operational steps (What to do or What to determine) of the knowledge base script and the name of provided steps, which are interconnected by the operating structure, each element of which contains its own information data block.

The information structure of data blocks consists of a set of data blocks having the following structure: the name of the data block; the content of the data block (entered from the keyboard); hyperlinks to external sources of information in Microsoft Office formats (video, audio, images, spreadsheets etc.), as well as to websites and web resources, including other xml scripts contained in the knowledge base. In accordance with the above, the general graph-structure of operational-structured scenarios of the knowledge base has the following form (Fig. 1).

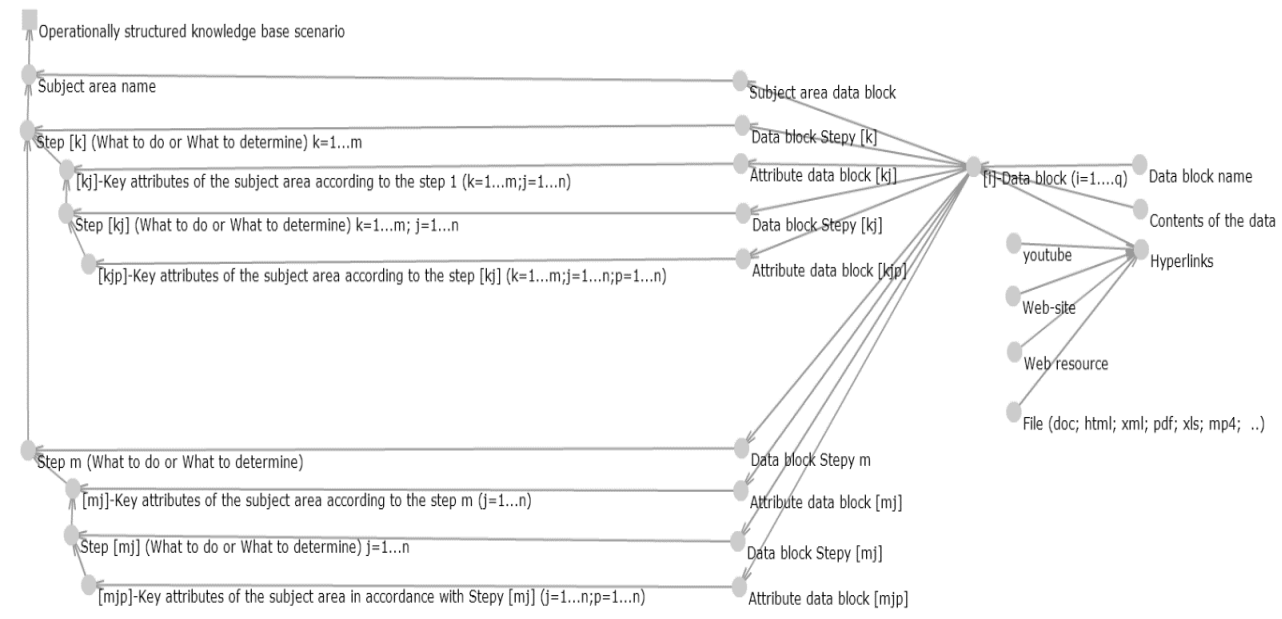

Fig. 1. The general graph-structure of the operational-structured scenario of the knowledge base

In practical terms, in the process of building a knowledge base script, an integrated information array is formed, which is formalized as an xml file stored in the knowledge base on the server as a standalone attribute, and if necessary joined as a key attribute to another knowledge base script.

In order to practically implement the above principles of knowledge base formation in the format of operational-structured scenarios, a Web-software complex "Editor of knowledge base scripts" was developed (Dovgy, Strizhak, Demyanenko, Kalnoy, Lisovy, Prikhodnyuk, Savchenko, Guralyuk, 2020; (http://work.inhost.com.ua).

Web-software complex "Knowledge Base Script Editor" is a network software and information tool for building operationally structured knowledge base scripts in xml file formats with their subsequent visualization in the form of "Knowledge Prisms".

Web-software complex "Knowledge Base Script Editor" has a wide format of use, from the creation of simple personalized knowledge bases in a given subject area, to complex-structured corporate knowledge bases. Its functionality provides the user with the 
necessary set of tools provided for the construction of various operational-structured scenarios of the knowledge base in a given subject area, their storage on a server or local media, search and visualization. The provided software package also makes it possible to combine or separate knowledge base scripts into other operationally structured xml knowledge base scripts, thus creating new trans disciplinary knowledge bases.

The main interface of the Web-software complex "Knowledge Baseline Script Editor" is presented in Fig. 2.

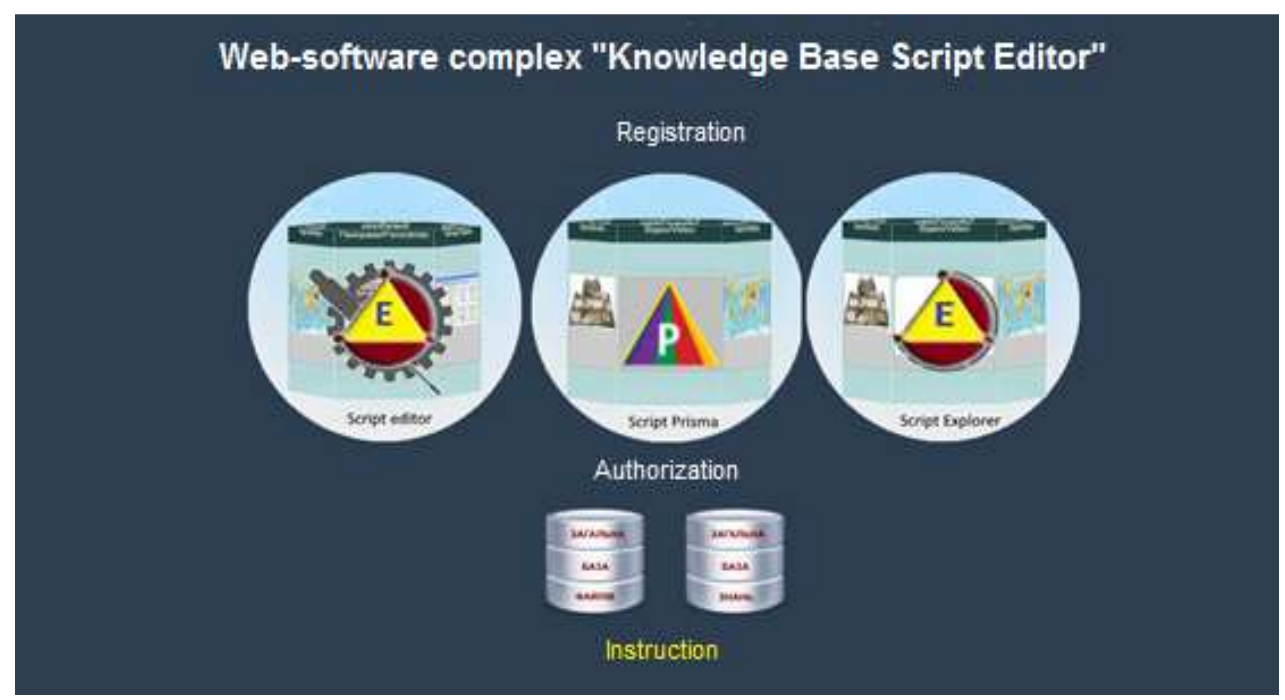

Fig. 2. The main interface of the Web software package "Knowledge Base Script Editor"

The general functional structure of the Web-software complex "Knowledge Base Script Editor" is presented in Fig. 3.

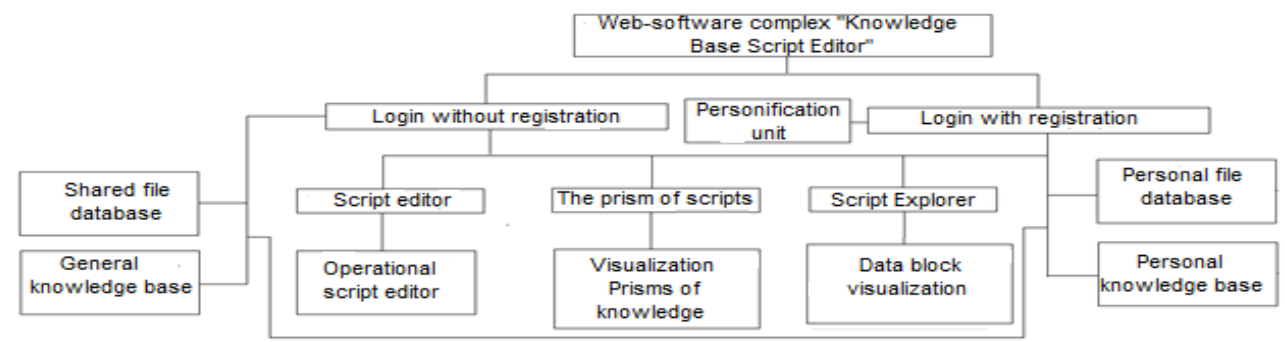

Fig. 3. General functional structure of "Web-software complex knowledge base script editor"

In accordance with the provided structure (Fig. 3), in the environment of the Web-software complex "Knowledge Base Script Editor", various knowledge base scripts are created, which are localized both on local magnetic media and in the network on the server, and which are further visualized (installed) in the format "Prism of knowledge". 
"Knowledge Prism" is a virtual electronic form of visualization of the xml script of the knowledge base in the form of a set of screens combined into a prism, each of which corresponds to a separate element of the operational structure of the script and contains interactive links to structured data blocks and nested "Prisms" according to the multilevel operating structure of the xml script. An example of visualization (installation) of the knowledge base scenario in the format "Knowledge Prism" is presented in Fig. 4.

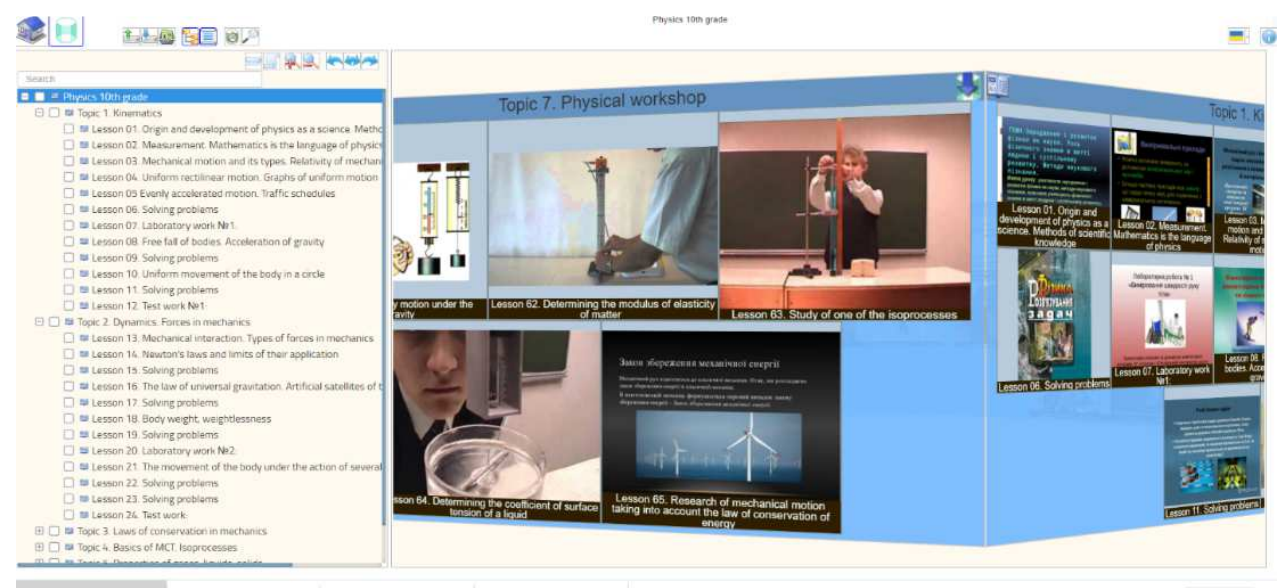

Fig. 4. Sample visualization of the knowledge base scenario in the format "Prism of knowledge"

In accordance with the provided "Prism of knowledge" (Fig. 4), to visualize the selected data block, which is represented by the corresponding image on the face of the prism, you need to activate it with the mouse cursor. In response to the monitor screen, its contents will be loaded (Fig. 5).

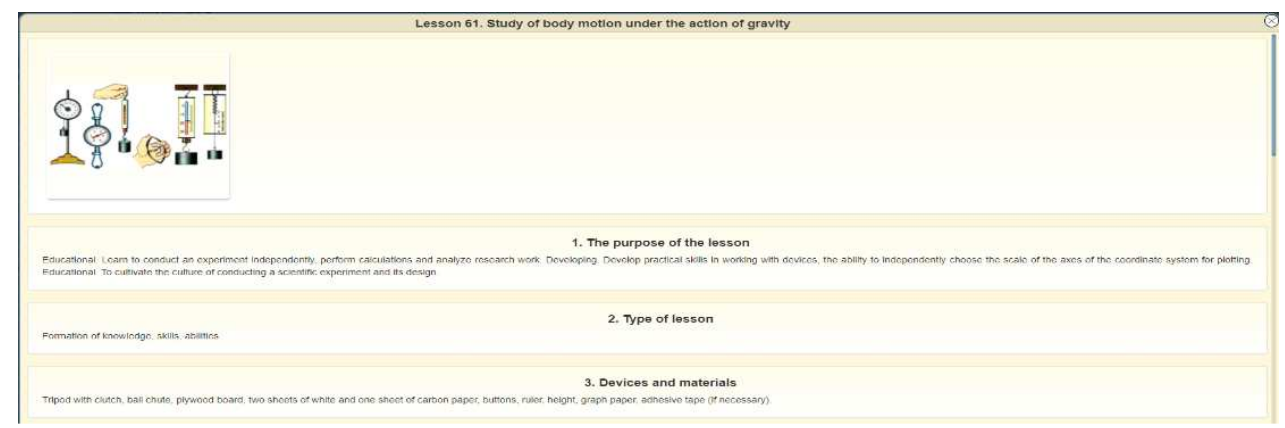

Fig. 5. Sample visualization of the knowledge block script block 


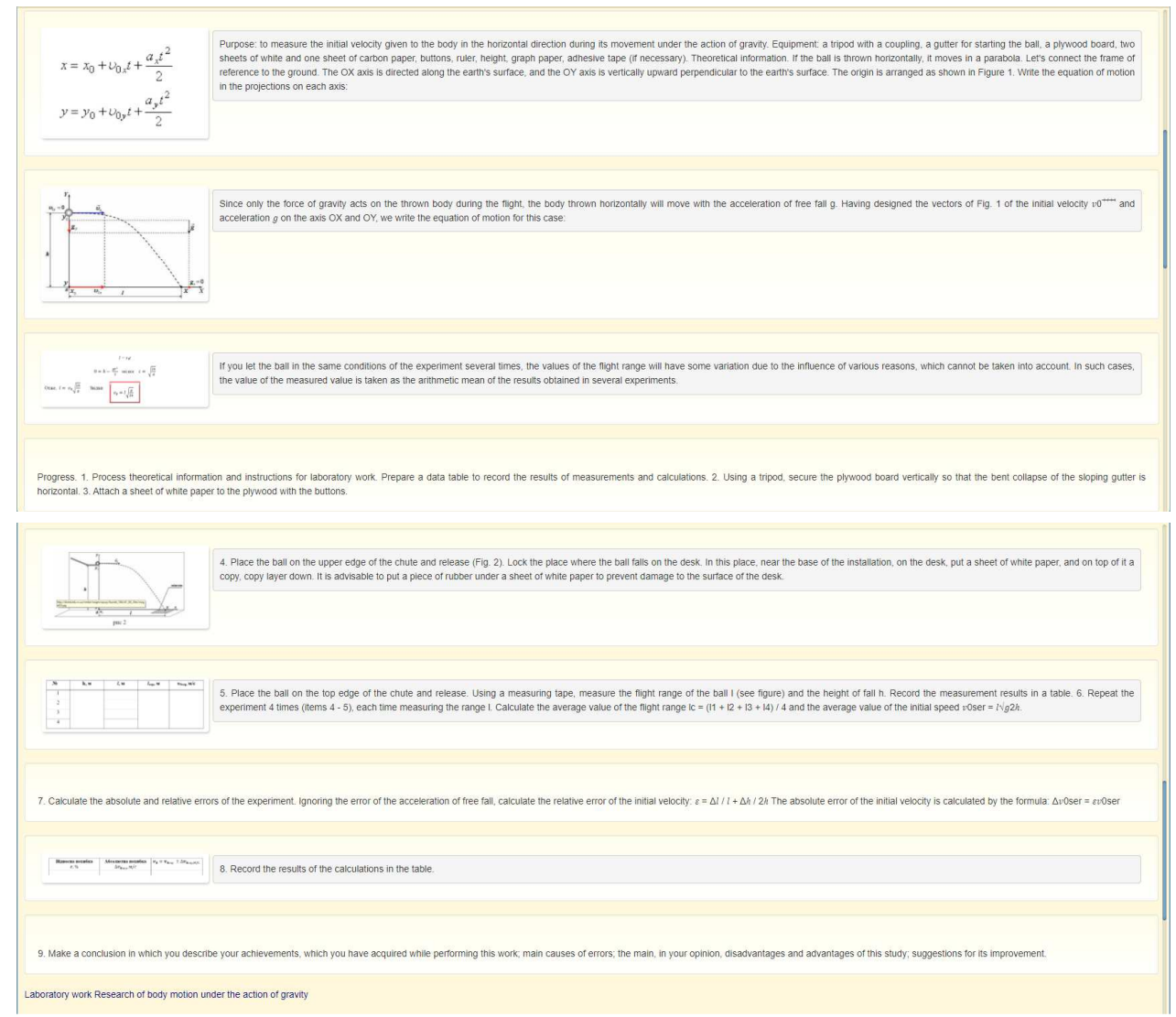

Fig. 5 (cont.). Sample visualization of the knowledge block script block

\section{CONCLUSIONS}

The described principles and means of network organization of information resources in the format of operationally structured xml scripts of knowledge base, using "Websoftware complex editor of knowledge base scripts" (hereinafter "software complex"), allow to create personalized and corporate object-oriented knowledge bases in a given subject area, which can be placed both on local magnetic media (eg flash media) and on the server, with their subsequent visualization in the format "Prisms of knowledge". This allows each user of the "software package" not only to create personal knowledge bases or corporate knowledge bases, but simply to use ready-made general knowledge bases for their work, or to exchange personal knowledge bases (xml knowledge base scenarios) with other users of the "software package".

The proposed approach is relevant, having a wide range of applications in various fields from training to production, as well as in everyday life to build interactive training programs, innovative production technologies, albums, tourist routes and more. 


\section{REFERENCES}

Palagin, A.V., Kryvy, S.L., Petrenko, N.G. (2012). Ontological methods and means of processing subject knowledge. Lugansk: izd-vo VNU im. V. Dalia.

Boland, R.J. Jr., Singh, J., Salipante, P., Aram, J.D., Fay, S.Y., Kanawattanachai, P. (2001). Knowledge representations and knowledge transfer. "The Academy of Management Journal" 44 (2).

Dalkir, K., Liebowitz, J. (2011). Knowledge Management in Theory and Practice. The MIT Press.

Krótkiewicz, M., Wojtkiewicz, K. (2009). Knowledge Acquisition in Conceptual Ontological Artificial Intelligence System. Human-Computer Systems Interaction. AISC, Vol. 60.

Krótkiewicz, M., Wojtkiewicz, K. (2005). Conceptual ontological object knowledge base and language. Computer Recognition Systems Proceedings of the 4th International Conference on Computer Recognition.

Leech, S.A., Sutton, S.G. (2002). Knowledge management issues in practice: Opportunities for research. "International Journal of Accounting Information Systems" 3 (2).

Leitner, K., Warden, C. (2004). Managing and reporting knowledge-based resources and processes in research organizations: Specifics, lessons learned and perspectives. "Management Accounting Research" (March).

Nuremberg, S., Raskin, V. (2004). Ontological Semantics. Cambridge: The MIT Press.

Pugh, K., Prusak, L. (2013). Designing effective knowledge networks. MIT Sloan Management Review (Fall): 79-88.

O'Leary, D.E. (2016). KPMG knowledge management and the next phase: Using enterprise social media. "Journal of Emerging Technologies in Accounting" 13 (2).

Bera, P., Andrew Burton-Jones, A., Wand, Y. (2011). Guidelines for Designing Visual Ontologies to Support Knowledge Identification. "MIS Quarterly". Vol. 35, No. 4.

Kalnou, S. (2019). Ontological Model of E-Scenario Research as a Means of Organizing Operational Research Knowledge Base. "Theory and practice of science education", Vol. 1(1). Kalna-Dubinyuk, T.P., Rogoza, K.G., Samsonova, V.V. et al. (2019). Interactive consulting system for rural tourism. Kyiv 2019.

Demyanenko, V.B., Kalnoy, S.P., Strizhak, O.E. (2013). Ontological aspects of building an e-script for supporting the process of scientific research of students of the Small Academy of Sciences of Ukraine / Information technology in education: Collection of scientific papers. Issue 15. Kherson: KSU.

Kalnoy, S.P. (2019). The principle of network organization of educational resources in the format of knowledge base scenarios and the means of their installation in the format of "knowledge prism". Scientific notes of the Small Academy of Sciences of Ukraine. Series "Pedagogical Sciences". Kyiv: National Center "Small Academy of Sciences of Ukraine", 2019. Issue. 14.

Kalnoy, S.P. (2017). E-scenario of organization of ontological corporate knowledge base as a means of information support of scientific research / S.P. Kalnoy // Problems of innovation and investment development. "Scientific and practical journal” № 12. 2017.

Kalnoy, S.P. (2017). Conceptual model of organization of corporate knowledge base as a means of information support of STEM - education / S.P. Kalnoy // Scientific Notes of the Small Academy of Sciences of Ukraine. Series "Pedagogical Sciences": Coll. Science. wash. Kyiv: Institute of Gifted Children of the National Academy of Pedagogical Sciences of Ukraine, № 10 . 
Dovgy, S.O., Strizhak, O.E., Demyanenko, V.B., Kalnoy S.P., Lisovy, O.V., Prykhodniuk, V.V., Savchenko, I.M., Guralyuk, A.G. (2020). A set of methodological tools for creating and using network educational systems based on the use of ontological models of description of functional objects and processes: WEB-software complex "Editor of ontological scenarios of knowledge base": Methodological recommendations for creating electronic educational resources based on cognitive services scenarios. Kyiv: National Center "Small Academy of Sciences of Ukraine" 2020.

DOI: $10.7862 /$ rz.2020.mmr.27

The text was submitted to the editorial office: December 2020.

The text was accepted for publication: December 2020. 
